\title{
Earth Specific Resistance Estimation from Earth Geology using Decision Trees Classification Algorithm
}

\author{
Ümit Çiğdem Turhal ${ }^{1}$, Abdullah Büyükışıklar \\ Electric-Electronics Engineering, Bilecik Şeyh Edebali University, Bilecik, Turkey ${ }^{1}$ \\ Institute of Science, Bilecik Şeyh Edebali University, Bilecik, Turkey ${ }^{2}$
}

\begin{abstract}
The electrical resistance in an earthing system basically consists of resistance of earthing conductors that is negligible and earth transresistance that depends on earth specific resistance varies with earth geology. In our country, designs are made considering earth specific resistance as $100 \Omega$ without making any measurements in most practices because these measurements are time consuming and costly. But this may cause important security gaps. This study is carried out to determine the answer of the question whether earth specific resistance could be determined without making any measurements? In this study geological data-earth specific resistance relation is modelled with decision tree classification algorithms in Weka software environment. The study is performed on the field that is located in Turkey. Estimation results yielded significant outputs. We expect this study to be pioneer for more widespread practices enhancing field diversity.
\end{abstract}

Keywords: Classification model, data mining, decision tree algorithm, earth specific resistance, earthing system, geological structure.

\section{INTRODUCTION}

Electrical protection could be defined as preventing electric current from passing through a false place or letting it pass in a dimension and time without giving any harm. One of the protection means in power installations are earthing systems that is primarily concerned with safety, in particular the prevention of electrical shock risks to life. In this context, an earthing system should be within the values to overcome faults and leakage currents. For this purpose, earthing systems should be designed, tested and maintained in such a way that it could meet this basic requirement $[1,2]$. In order for this system to enable expected protection, electrical resistance of the device to be earthed from the body to earth should be low enough. This electrical resistance basically consists of resistance of earthing conductors and earth transresistance of earthing conductors. Since resistance of earthing conductors is negligible, main significant resistance in the system is earthing transresistance of earthing conductors.

Earthing transresistance value is calculated dependent on the type of earthing conductor used in earthing systems, earthing method and earth specific resistance (ESR) varying with geological structure of the earth. According to the results of the measurements carried out in various parts of the world, specific resistance (SR) of the earth surface has a value range between 2 to $10.000 \Omega \mathrm{m}$. Besides, geomorphologic studies reveal that ESR may not have the same values even for the same type of rock in different regions. This shows that it is likely to make big mistakes in SR estimations in the regions where SR measurement is not possible [3]. Considering the importance of measuring ESR and system earthing resistance correctly by means of electrical safety, it can be seen that there is a need for more accurate SR estimations. In this sense, efforts to associate ESR with geological structure date back to old times [3-7]. In general, these studies can be studied under two major topics. One is about determination of under earth structures. Upon analysing literature, there exist a number of studies within a wide range. Some of these could be specified as soil examinations of engineering constructions [8], investigation of under earth water and environmental pollution [9-11], under earth water and geothermal research [12], mine research [13], archaeological research and oil research [14]. As can be seen, the studies in this part are concerned with determination of geological structure from SR within ESR-geological structure relation. The other one is about evaluation and relation ESR and earth geology of that area. In these studies, findings of various experimental analyses carried out can be seen. In these studies SR is measured at certain points and geological structures are also studied at these points. Thus, electrical measurement results and geological structure evaluations are associated and generalized, in this way conventional tables are obtained to show possible ESR values for various kinds of earth. In these preliminary studies, only regional geology, that is, earth layers lying right beneath earth and other loose surface materials are taken into account [3]. Nevertheless, while 


\section{International Journal of Innovative Research in Electrical, Electronics, Instrumentation and Control Engineering}

\section{ISO 3297:2007 Certified}

Vol. 5, Issue 3, March 2017

comparing measurement results and geological structures, inconsistent and sometimes inexplicable findings are found. In the light of these findings, it is concluded that regional geology alone is ineffective to determine ESR and that instead, deeper geological structure in earth structure is to be taken into account since earth has no regular structure. Hence, assumption of a consistent SR is practically not valid. In earth layers, changes in depth lead to changes in SR values. For this reason, SR measurements should be performed regionally and in regions deeper below the surface [15-18].

Considering the situation of earthing standards of today, we can see that in Turkey and even in developed countries such as the United Kingdom and the United States of America, ESR is mostly determined in terms of certain standards without making measurements, which could lead to extremely important security gaps [15]. In Turkey, following Kocaeli earthquake in 1999, it is obliged to use geological data during construction of structures possessing power installations. The aim here is to determine to what extend the region carries risk of earthquake in view of data obtained. But in this study, we studied disponibility of data obtained from the geological structure study carried out to determine risk of earthquake in estimation of ESR value.

In the study, we determined a residential area of $14.000 .000 \mathrm{~m} 2$ having border to Bursa-Eskişehir-Ankara highway as pilot region and used geological features in depths of $0-3 \mathrm{~m}, 3-10 \mathrm{~m}$ and $10-20 \mathrm{~m}$ of earth, respectively beside the layers of earth's crust lying just beneath earth and other loose surface materials. Places of borehole points in the region are found and ESR measurements are performed at these points. To perform this estimation, classification models are set with decision tree classification algorithms in Weka software environment using databases formed by geological data and ESR measurements and availability of ESR is studied without making measurements solely by using geological structure knowledge. In the rest of the paper; in Chapter 2 materials used in this study are introduced and classification algorithms used in modelling are explained, in Chapter 3 development of ESR estimation model is given. In Chapter 4 results and discussion are introduced and in Chapter 5 conclusion is given.

\section{MATERIAL AND METHOD}

\section{A. Material}

Your Two kinds of materials are used for this study: Geological data and ESR measurements. The geological data determined in the context of the obligatory during construction of building having power installation are obtained from İnegöl city hall. The ESR data measurements are performed by us. Both of the data are obtained for 41 boreholes in the field of study. Then these data are used to construct and test the model to estimate the ESR value from earth geology.

\section{- Geological Data}

Field of study, whose site location map and geographical map is given in Figure 1, is located within the borders of the districts of Akhisar and Çakırçiftliği of İnegöl in the city of Bursa, being $40 \mathrm{kms}$ away from Bursa and $5 \mathrm{kms}$ from İnegöl. In the west, it is adjacent to Bursa-EskişehirAnkara highway.

Field of study covers an area of 1060ha 10.600.000 m2. It is surrounded with Karalar Village on the North, BursaAnkara highway on the South, Industrial Zone on the east and the districts of Çakırçiftliği on the west. Field measurements are carried out between 08.04.2006 and 30.05.2006, and in the measurements an acker type rotary driller mounted on the lorry is used, and also a geological engineer, a driller and two assistant drillers are assigned.

In field studies, drilling is performed by carrying out a standard penetration test (SPT) every 1,5 meters in aqueous system and by taking damaged, undamaged and borehole samples with reference to general characteristics based on geological-geotechnical research principles.

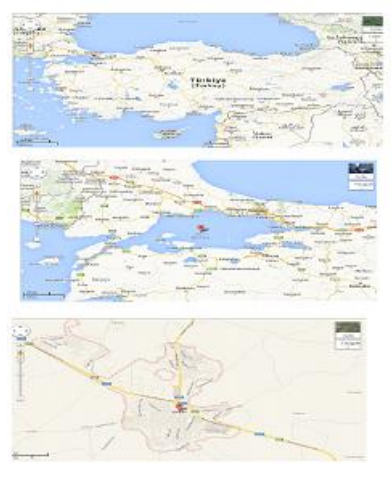

(a)

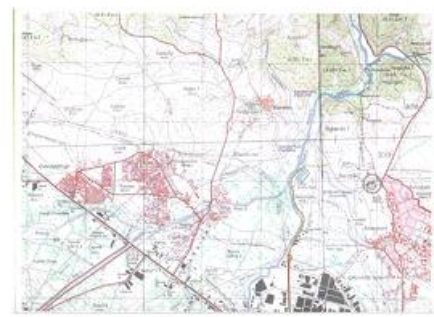

(b)
Figure 1. Measuring Range a) Site Location Map b) Geographical Map[19]

In the region are 41 boreholes. For the depths of $0-20$ meters, geological data obtained from these boreholes include characteristics such as moisture, rigidity, absolute material, proportional mixture and little mixture. In this study, however, data from only 20 boreholes in the region are used since data from the rest of the boreholes included some ambiguous values. Geological data from one sample borehole are given in Table 1 .

- Earth Specific Resistance (ESR) Data Measurements In this study ESR measurements are performed using Wenner method for borehole points in the field. Detection of borehole point coordination by means of Universal Transverse Mercetor (UTM) format in meters are performed using maps given in Figure $2 a$ and Figure $2 b$. Afterwards, the same cadastre plan given in Figure 3 is matched up with the geographical map given in Figure 1b and current coordinates of corner points of cadastral map sheets in terms of UTM are specified in conversion map of latitude into longitude in the cadastre plan and then they 


\section{International Journal of Innovative Research in Electrical, Electronics, Instrumentation and Control Engineering}

\section{ISO 3297:2007 Certified}

Vol. 5, Issue 3, March 2017

are converted into degrees. With the conversion, Wenner method. Measurement results obtained varied coordinates of borehole points are defined in terms of within the range of $0-60 \Omega$.

degrees and for 40 borehole points ESR are measured by

TABLE I GEOLOGICAL DATA FOR A SAMPLE BOREHOLE

\begin{tabular}{|l|l|l|l|l|l|}
\hline Depth $(\mathrm{m})$ & Moisture (\%) & Rigidity & Absolute Material & Proportional Mixture & Little Mixture \\
\hline $0-3$ & 24.2 & Loose & Riprap & Riprap & Sand \\
\hline $3-10$ & 36.8 & $\begin{array}{l}\text { Medium stiff(3- 6) } \\
\text { /Stiff(6-10) }\end{array}$ & Clay & Clay & Sand \\
\hline $10-20$ & 29.3 & Loose(3-6)/Stiff(6-10) & Sand & Gravel & Silt \\
\hline
\end{tabular}

In ESR measurements there are several classical techniques [20]. As shown in Figure 4, the Wenner technique is the commonly used one. This technique uses four equally spaced, short electrodes placed in a straight line and the same depth of penetration, resistivity measurements depend on the distance between electrodes and soil resistivity, and conversely do not depend significantly on the size and material of the electrodes, although it depends on the kind of contact is made with the earth. The basic principle of this method is the injection of a DC or low frequency through the earth between two electrodes $\mathrm{C} 1$ and $\mathrm{C} 2$ while the potential which is measured between two electrodes $\mathrm{P} 1$ and P2. These electrodes are buried in a straight line and equally spaced between them. The ratio of V/I is known as the apparent resistivity. The apparent resistivity of the ground is a function of the resistance and geometry of the electrode. In performing the Wenner test, it is assumed that the electrodes are small and shallowly inserted and that the earth is horizontally uniform.

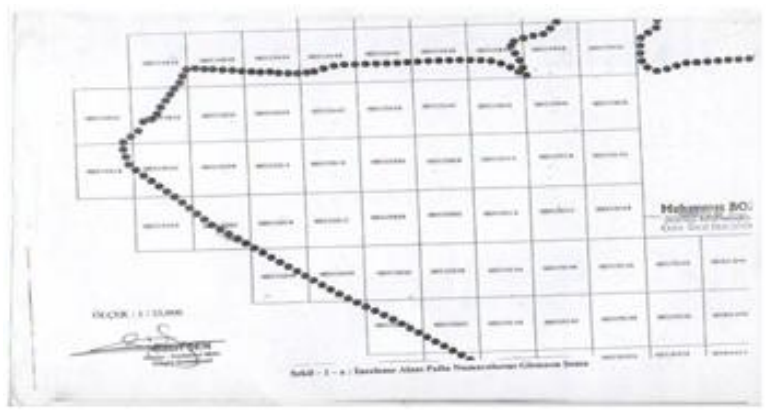

(a)

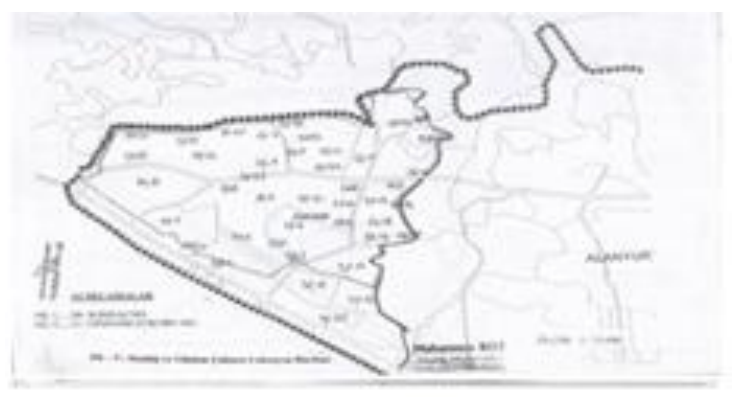

(b)

Fig. 2. Measuring Range a) Site Location Map b) Geographical Map

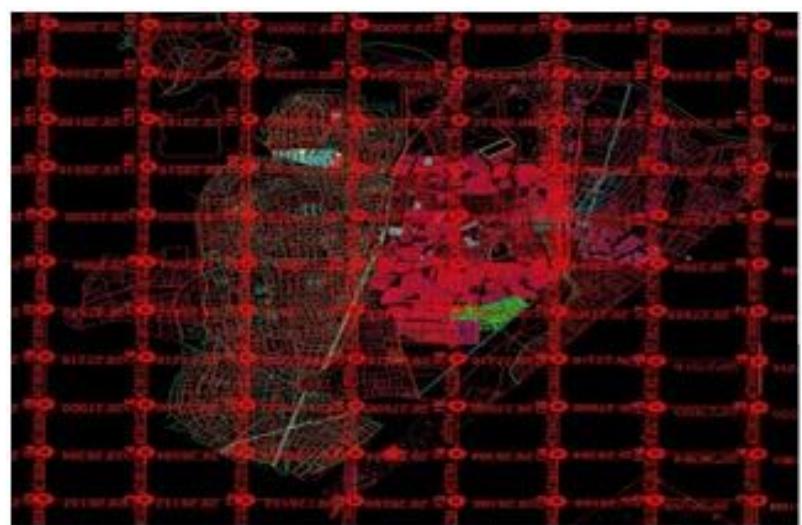

Fig. 3. Cadastre plan conversion map of lattitude into longitude

\section{B. Method}

Process of searching for correlations and rules that enable us to make estimations about future is called data mining [21]. One important issue of data mining is classification attracting great attentions by researchers. Classification defined as discretisation of data with respect to common characteristics they involve, consists of assigning a class label to a set of unclassified cases. The objective of classification is to analyze the input data and to develop an accurate description or model for each class using the features present in the data. This model is used to classify test data for which the class descriptions are not known [22].

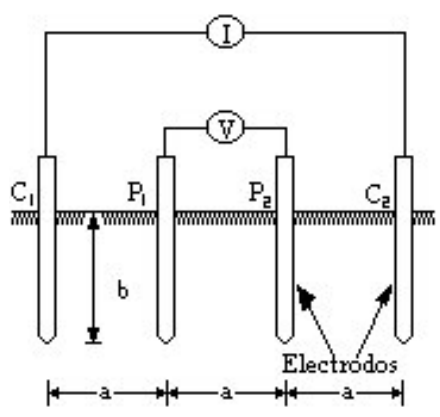

Fig. 4. Wenner configuration

In general there are two types of classification: Supervised and unsupervised. In supervised classification the set of possible classes is known in advance. The input data, also 


\section{ISO 3297:2007 Certified}

Vol. 5, Issue 3, March 2017

called the training set, consists of multiple records each having multiple attributes or features. Each record is tagged with a class label. In unsupervised classification set of possible classes is not known. After classification we can try to assign a name to that class and it is called clustering. In literature, there are many classification methods used [22]. Some of these are decision trees, Bayes classifiers, artificial neural networks, etc.

Decision trees are used commonly in classification models since they are easier to structure and to understand compared to other methods [23] and also provide a useful solution for a good number of classification problems where large data bases are used and for complicated or mistaken information. This method is a simple recursive structure for expressing a sequential process in which a case, described by a set of attributes, is assigned to one of a disjoint set of classes. Each leaf of the tree denotes a class. An interior node denotes a test on one or more of the attributes with a subsidiary decision tree for each possible outcome of the test. The process of classifying a case starts at the root of the tree. If this is a leaf, the case is assigned to the nominated class; if it is a test, the outcome for this case is determined and the process continued with the subsidiary tree appropriate to that outcome.

In this study, a classification model is developed in order to estimate the ESR using earth geology. First the ESR estimation model is developed by using decision trees classification algorithm that is a supervised technique. In the application four different decision tree classification algorithms are used. These are J48, LADTree, NBTree and RandomForest. Then to make sense of and interpret the results k-nearest neighbour clustering algorithm that is an unsupervised classification method is used in order to see the range of the ESR values in the field of study. The brief explanation of the used classification algorithms are given below.

\section{- J48}

This method uses C4.5 algorithm, which is an improved application of ID3 algorithm. In learning period this method uses the concept of normalised knowledge acquisition. This concept is a division criterion used to select the feature which could divide the pattern set that goes into each tree node effectively. For all the nodes to be formed, an equivalent value is found using a qualification that gives the highest yield in that node. By this threshold value, a rule is formed which could divide the related node into branches. Each node is divided into two branches according to whether the inequality is right or wrong. This process is repeated until leaf nodes are reached. Each leaf node represents a different class [24].

\section{- 2) LADTree}

It produces a multiclass for decision tree, that is, it can perform more than two class entries and carry out logistic regression using logitoot strategy [25].
- 3) NBTree

This decision tree is a hybrid method which is a combination of simple Bayesian and decision tree methods. The only characteristic of this method that distinguishes it from classical recursive solution method is that each of the leaf nodes reaches a decision using NB classifier. An important characteristic of this method is the assumption that features found on the basis of NB-based methods are independent of each other [26].

\section{-4) RandomForest}

This method uses a great number of decision trees. While forming random forest, bagging method is used and in each tree node, random feature selection is performed [27].

\section{III.DEVELOPMENT OF ESR ESTIMATION MODEL}

The ESR estimation from earth geology performed on Weka software is actually development of a classification model. This process can be summarized as follows:

First Step: A database is constructed using the geological data and ESR measurements given in previous chapter. In Table 2, a database template is given. In this pattern each row corresponds to a sample datum. Columns show the different attributes of this sample. The column on the far right is the class attribute of data. In the pattern, $\mathrm{m}$ separate samples with n separate attributes can be seen. In our database geological features such as moisture, rigidity, absolute material, proportional mixture and little mixture are used as attributes and ESR measurement values are used as the class attribute. Then this database is used in order to obtain the training set and test set that are used in the application.

Second Step: In this step using training set that consists of multiple records tagged with a class label, different ESR estimation (classification) models are constructed using J48, LADTree, NBTree and RandomForest algorithms in Weka software.

Third Step: In this step the performance analyses of these classification models are carried out using test set. Thus all the records in the test set are classified using these models and confusion matrix [28] is constructed according to the classification results. The performance of the model is presented by using this matrix then the developed classification model can be used to estimate the ESR value (class label) of a sample soil which only geological features are known.

\section{A. Database}

The The database is constructed by using the material given in Table 1 and the ESR measurement values based on the template given in Table 2. In the database there are both numerical and also categorical values. For example moisture and ESR measurements are numerical and the remaining are categorical values. In order to make the 


\section{ISO 3297:2007 Certified}

Vol. 5, Issue 3, March 2017

database available for the classification algorithms some pre-processing are applied to the data. Accordingly, class info (ESR value) defined as numerical value is converted into categorical value. For this conversion, ESR values varying within the range of $0-60 \Omega$ are divided into intervals and a categorical value assignment is performed in response to numerical data within this interval. This value assignment is applied for 3 different class scenarios. ESR values are divided firstly into 2 different intervals as to be 2 groups, secondly into 3 different intervals as to be 3 groups and finally into 5 different intervals as to be 5 groups, thus three basic databases are formed including different number of class attribute for data with the same geological characteristics. SR intervals and categorical value assignments can be seen in Table 3. Experimental studies given in the next chapter are performed separately for each of these three different class scenarios in each time.

TABLE III SAMPLE DATABASE

\begin{tabular}{cccc}
\hline \hline $\begin{array}{c}\text { Sample } \\
\text { No }\end{array}$ & A $1 \ldots \ldots \ldots \ldots \ldots \ldots \ldots \ldots \ldots \ldots \ldots$ An & Class \\
\hline 1 &. & $\cdot$ & $\cdot$ \\
. &. & $\cdot$ & $\cdot$ \\
$\cdot$ &. & $\cdot$ & $\cdot$ \\
$\cdot$ &. & $\cdot$ & $\cdot$ \\
&. & $\cdot$ & $\cdot$ \\
$\mathrm{m}$ &. & $\cdot$ & $\cdot$
\end{tabular}

A1,......, An are the $n$ different attributes of the samples

TABLE IIIII CATEGORICAL VALUE ASSIGNMENT TO ESR VALUES

\begin{tabular}{crrc}
\hline \hline Numerical & \multicolumn{3}{c}{ Corresponding categorical value } \\
\cline { 2 - 4 } Value $(\Omega)$ & 2Class & 3Class & 5Class \\
\hline $0.01-10$ & $\mathrm{a}$ & $\mathrm{a}$ & $\mathrm{a}$ \\
$10.01-20$ & $\mathrm{a}$ & $\mathrm{a}$ & $\mathrm{b}$ \\
$20.01-30$ & $\mathrm{a}$ & $\mathrm{b}$ & $\mathrm{c}$ \\
$30.01-40$ & $\mathrm{~b}$ & $\mathrm{~b}$ & $\mathrm{~d}$ \\
$40.01-50$ & $\mathrm{~b}$ & $\mathrm{c}$ & $\mathrm{e}$ \\
$50.01-60$ & $\mathrm{~b}$ & $\mathrm{c}$ & $\mathrm{f}$ \\
\hline \hline
\end{tabular}

A sample of basic database used for this study is given in Table 4. Geological features such as moisture, rigidity and etc. set attributes for borehole and ESR value shows class information.

\section{B. Database}

In this paper, 3 different experimental studies are performed in order to estimate ESR value from earth geology using J48, LADTree, NBTree and RandomForest decision trees classification algorithms. In order to do this new databases are generated in compliance with application from the database a sample of which is given in Table 4. Each experimental study is repeated for three times for the same database that includes same geological characteristics but different categorical value assignments of class attribute as is seen in Table 3 such that 2 class, 3 class and 5 class scenarios. Studies are carried out in Weka software environment and " 10 -fold cross verification method" is used as test method. In this method, data source are divided into 10 sections each section is used once as test sequence and the rest 9 sections as learning section.

TABLE IVV

\begin{tabular}{l|llllll}
\multicolumn{7}{c}{ A SAMPLE DATABASE FOR A BOREHOLE } \\
\hline $\begin{array}{l}\text { Samp } \\
\text { le }\end{array}$ & Attributes & Class & & & \\
& & & & & & \\
\hline Hole & $\mathrm{M}_{1} /$ & $\mathrm{R}_{1} /$ & $\mathrm{AM}_{1} /$ & $\mathrm{PM}_{1} /$ & $\mathrm{LM}_{1} /$ & ESR \\
No & $\mathrm{M}_{2} /$ & $\left(\mathrm{R}_{2}-\mathrm{R}_{3}\right) /$ & $\mathrm{AM}_{2} /$ & $\mathrm{PM}_{2} /$ & $\mathrm{LM}_{2} /$ & \\
& $\mathrm{M}_{3}$ & $\left(\mathrm{R}_{4}-\mathrm{R}_{5}\right)$ & $\mathrm{AM}_{3}$ & $\mathrm{PM}_{3}$ & $\mathrm{LM}_{3}$ & \\
& $24.2 /$ & $\mathrm{L} /$ & $\mathrm{Riprap} /$ & $\mathrm{Riprap} /$ & Sand/ & a \\
& $36.8 /$ & $(\mathrm{MS}-\mathrm{S})$ & Clay/ & Sand/ & Gravel/ & \\
& 29.3 & (L-S) & Sand & Gravel & Silt & \\
\hline
\end{tabular}

$\mathrm{Mi}(\mathrm{i}=1,2,3)$ : Moisture for $(0-3 \mathrm{~m}),(3-10 \mathrm{~m})$, and (10-20m) respectively. $\mathrm{Ri}(\mathrm{i}=1, . .5)$ : Rigidity for $(0-3 \mathrm{~m}),(3-6 \mathrm{~m}),(6-10 \mathrm{~m}),(10-15 \mathrm{~m})$ and $(15-$ $20 \mathrm{~m})$ respectively.

$\mathrm{AM}_{\mathrm{i}}(\mathrm{iI}=1,2,3)$ : Absolute Material for $(0-3 \mathrm{~m}),(3-10 \mathrm{~m})$, and $(10-20 \mathrm{~m})$ respectively.

$\mathrm{PM}_{\mathrm{i}}(\mathrm{iI}=1,2,3)$ : Proportional Mixture for $(0-3 \mathrm{~m}),(3-10 \mathrm{~m})$, and $(10-20 \mathrm{~m})$ respectively.

$\mathrm{LM}_{\mathrm{i}}(\mathrm{iI}=1,2,3)$ : Little Mixture for $(0-3 \mathrm{~m}),(3-10 \mathrm{~m})$, and (10-20m) respectively.

ESR: Earth Spesific Resistance value in Ohms.

L: Loose

MS: Medium Stiff

S: Stiff

On this basis:

In the first experimental study, classification models are formed using the database a sample of which is given in Table IV. In this database each sample includes 5 different geological attribute values varying with depth such as moisture, rigidity, proportional mixture, little mixture and also the class information. As we have 3 different depth information to be $0-3 \mathrm{~m}, 3-10 \mathrm{~m}$, and $10-15 \mathrm{~m}$ for each geological attribute the database used in the first experimental study includes 15 geological attributes and also the class information. Thus a sample can be represented with a 1x16 dimensional feature vector. According to the classification results, the highest performance is achieved for J48 algorithm for all different number of class scenarios. This is followed by LADTree, RandomForest and NBTree algorithms. Another result is that the highest success of estimation is obtained in 2Class scenario of the class information.

In the second experimental study: Classification models are formed including only one of the geological characteristics such as rigidity, moisture and etc. for the depths of $0-3 \mathrm{~m}, 3-10 \mathrm{~m}$ and $10-20 \mathrm{~m}$. In this sense, models are formed using database a sample of which is given in Table 5. Hence, the effect of geological characteristics on their own on determining ESR value is examined. 3 different classification models are constructed for 3 different categorical value assignments of the class 
information. According to the classification results, the highest estimation performance is achieved for humidity attribute followed by rigidity in 2Class scenario using RandomForest algorithm. This is then followed by J48LADTree and NBTree algorithms.

In the third experimental study: Classification models are formed using databases a sample of which is given for the depth of $0-3 \mathrm{~m}$ in Table 6 that includes geological properties belong to only one of the depths of $0-3 \mathrm{~m}, 3-$ $10 \mathrm{~m}$, or $10-20 \mathrm{~m}$. This study is performed for all of the 3 different depths and 3 different categorical value assignments of the class information for each depth separately. Thus, the effect of the value of depth in determining the ESR value is examined. According to the classification results it is found that $0-3 \mathrm{~m}$ and $10-20 \mathrm{~m}$ depth info is more efficient in ESR estimation from earth geology than that of $3-10 \mathrm{~m}$ depth information. The highest estimation performance is again obtained for 2 Class scenarios.

\section{TABLE V A SAMPLE DATABASE USED FOR SECOND} EXPERIMENT

\begin{tabular}{llcll}
\hline \hline Hole No & Moisture & Properties & Moisture \\
& $0-3 \mathrm{~m}$ & $3-10 \mathrm{~m}$ & Moisture & Class \\
& \multirow{2}{*}{1} & $36-20 \mathrm{~m}$ & \\
\hline \hline
\end{tabular}

\section{TABLE VV A SAMPLE DATABASE FOR 0-3M DEPTH}

\begin{tabular}{lllllll} 
Hole & & \multicolumn{3}{c}{ Properties } & & Class \\
No & & & & & & \\
& $\mathrm{M}_{1}$ & $\mathrm{R}_{1}$ & $\mathrm{AM}_{1}$ & $\mathrm{PM}_{1}$ & $\mathrm{LM}_{1}$ & \\
1 & 24.2 & Loose & Riprap & Riprap & Sand & a
\end{tabular}

$\mathrm{M}_{1}$ : Moisture for $(0-3 \mathrm{~m})$

$\mathrm{R}_{1}$ : Rigidity for $(0-3 \mathrm{~m})$.

$\mathrm{AM}_{1}$ : Absolute Material for $(0-3 \mathrm{~m})$.

$\mathrm{PM}_{1}$ : Proportional Mixture for $(0-3 \mathrm{~m})$.

$\mathrm{LM}_{1}$ : Little Mixture for $(0-3 \mathrm{~m})$

\section{IV.RESULTS AND DISCUSSIONS}

In this paper, a data mining application is performed in which ESR is estimated using geological characteristics of earth. In order to do this geological data-ESR relation is modelled with decision trees classification algorithms that are J48, LADTree, NBTree and RandomForest in Weka software environment. Various type of experimental studies in which different databases used are carried out. The basic database is constructed using all the geological data of the pilot region and also the ESR measurements. Then different databases are also constructed using this basic database. For example the database used in the second experimental study includes only one type of the geological property changes with depth. Thus each time the effect of different geological properties on estimation of ESR using earth geology is analyzed. Results obtained in the experimental studies are as follows:
-- Upon analysing all the results obtained, best model performances are achieved in databases in which categorical value assignment for the ESR value as to be 2 Class and success of $80 \%$ is obtained as the highest performance rate. Performance rate is seen to decrease as the number of class's increases. The reason for this is analysed. In this sense, a cluster analysis is performed on existing data. By cluster analysis, we determined how many different data groups exist in database. Accordingly, two separate data groups are obtained. Hence, higher performance is achieved in 2 class modelling since it has 2 separate data groups in the field of study.

-- It is observed that the moisture and the rigidity properties of earth are quite effective in estimation of ESR value from earth geology. Then these properties are followed by proportional mixture, absolute material and little mixture respectively.

-- In all algorithms, use of $0-3 \mathrm{~m}$ and $10-20 \mathrm{~m}$ depth characteristics are more efficient in ESR estimation compared to that of $3-10 \mathrm{~m}$ by means of performance.

-- From decision tree algorithms used for classification modelling, highest performance is achieved in RandomForest algorithm. This is followed by LADTree, J48 and finally NBTree algorithm.

\section{CONCLUSION AND FUTURE WORK}

Existing correlation analyses between earth specific resistance and geological structure date back to old times. In literature, there exist various studies used for determining some characteristics regarding geological structure from ESR. Unlike this, however, there are no studies in which an intelligent system is used for determining the ESR value from geological structure.

In this sense, some general and traditional tables are formed assigning possible SR values for certain types of rocks as a result of various experimental analyses. But as is seen from the literature survey while comparing measurement results and geological structures, inconsistent and sometimes inexplicable findings are found. The regional geology alone is ineffective to determine the ESR value and that instead, deeper geological structure in earth structure is to be taken into account. Hence, assumption of a consistent SR is practically not valid and SR measurements should be performed regionally and in regions deeper below the surface.

In this paper, an intelligent model to estimate ESR value from earth geology is proposed. In the study, SR estimation are performed using certain modelling algorithms which are data mining methods. Results yielded significant outputs. This study is important as to be the first regarding this issue. In the future work according to the results that show the importance of moisture and rigidity of earth in ESR value estimation wider analysis in terms of region and data variety are planned using other appropriate classification algorithms 


\section{International Journal of Innovative Research in Electrical, Electronics, Instrumentation and Control Engineering}

\section{ISO 3297:2007 Certified}

Vol. 5, Issue 3, March 2017

to increase the model performance. In this sense this study will carried out in a wider range and in various fields also considering meteorological data.

\section{ACKNOWLEDGMENT}

This paper is produced from the thesis study, accomplished at the Institute of Science of Bilecik Şeyh Edebali University in 2014.

\section{REFERENCES}

[1] BS7354, "Code of Practice for Design of High-Voltage OpenTerminal Stations", BSI, 1990.

[2] EA TS 41-24, "Guidelines for the Design, Installation, Testing and Maintenance of Main Earthing Systems in Substations", Electricity Association, 1992.

[3] R. H. Card, "Earth Resistivity and Geological Structure," Bell System Technical Journal 15.1 (1936): 167-171.

[4] K. Kasai, "Research on the Determination of the Conductivity of the Ground for the Calculation of the Mutual Impedance of Circuits with Earth Return," International Conference of Large Electric Networks, Paris, 1933, paper 88

[5] R. Mitsuda and K. Kanaya, "Interference Of Power Lines On Neighboring Aerial Communication Lines And Radio Receptions", World Power Conference, Tokyo, 1929, Trans., v. 2, p. 945-73.

[6] J. Collard, "Measurement of the Mutual Impedance of Circuits with Earth Re -Turn," Inst. Elec. Eng. JL, v. 71, 1932, p. 674-82.

[7] S. Whitehead, W. G. Radley, J. E. Pidgeon, and J. Collard, "Inductive Interference due to Earth Currents from Cable Systems," British Elec. and Allied Industries Res. Assoc., Tech. Rept. Ref. M/T 16, 1932.

[8] http://www.maden.org.tr/resimler/ekler/a15d41947a732c9_ek.pdf, 2011.

[9] M. Asçı, F. Özçep, T. Yas, and N. Alpaslan, "Görünür Özdirenc (Schlumberger) Verilerinin Sönümlü En Küçük Kareler (Marquardt) Tekniğiyle Modellenmesi" İstanbul Üniersitesi Müendislik Fakültesi Yerbilimleri Dergisi, 2004, 17(2):111-118.

[10] T. Dahlin, "2D Resistivity Surveying for Groundwater and Enviranmental Appications", First Break, 1996, 14:275-284

[11] M. G. Drahor, A. B. Meriç and T. O. Kurtulmuş, "Dolgu alanlarda özdirenç ters-çözüm modellemesi ve eski bir atık dolgu alanına uygulanması", Yerbilimleri, 2006, 27(3), 195-209.

[12] Ş. Çetin, A. R. Erdoğan and M. E. Özgüler, "Türkiye'deki Jeotermal Alanların Arastırılmasında Jeofizik Calıșmalar." Maden Teknik Arama Genel Müdürlüğü Dergisi, 1986, 107:152-158.

[13] A. Özdemir and I. Savaș, "Maden Aramacıllğında Bir Gelișim Cok Elektrotlu Özdirenç Görüntüleme", Madencilik Türkiye Dergisi, 2009, 2:24-29.

[14] A. Kopçal, "Hatay İli Yayladağ İlçesinde Özdirenç YöntemiyleYer Altı Suyu Aramaları", Yüksek Lisans Tezi, Çukurova Üniversitesi Fen Bilimleri Enstitüsü, Adana, 2009.

[15] J. A. Laver and H. Griffiths. "The variability of soils in earthing measurements and earthing system performance." Rev. Energ. Ren.: Power Engineering, School of Electrical Engineering, Cardiff University, UK , 2001: 57-61.

[16] R. G. van Nostrand and K. L. Cook, "Interpretation of Resistivity Data", Geological Survey Professional Paper 499, US Government printing office, 1966

17] G. F. Tagg, "Measurement of Earth-Electrode Resistance with Particular Reference to Earth-Electrode Systems Covering a Large Area", Proc. IEE, 1964, Vol.111, No.12.

[18] F. Dawalibi and D. Mukhedkar, "Ground Electrode Resistance Measurements in Non-Uniform Soils", IEEE Trans. PAS, 1974, vol.93, No.1.

[19] Years, "Bursa İnegöl Akhisar-Çakırçiftliği mahallelerine ait İmar Planına Esas Jeolojik- Jeoteknik Etüd Raporu”, Bursa, 2006.

[20] G. F. Tagg, “Earth Resistances”, Newnes, London, 1964
[21] Alpaydın, E., "Zeki Veri Madenciliği: Ham Veriden Altın Bilgiye Ulaşma Yöntemleri.", Bilişim 2000 Veri Madenciliği Eğitim Semineri, İstanbul, 2000, 1086-1095.

[22] M., Manish, R. Agrawal and J. Rissanen. "SLIQ: A fast scalable classifier for data mining." Advances in Database TechnologyEDBT'96. Springer Berlin Heidelberg, 1996, 18-32.

[23] R. Agrawal, T. Imielinski and A. N. Swami, "Mining association rules between sets of items in large databases", In Proceedings of the 1993 ACM SIGMOD International Conference on Management of Data, (Editörler P. Buneman and S. Jajodia), İshington, D.C., 207216, 1993.

[24] Dunham, M.H. "Data Mining: Introductory and Advanced Topics", Prentice Hall, Upper Saddle River, NJ., 2003.

[25] R. Blagojevic, B. Plimmer, J. Grundy, Y. Wang, "Using data mining for digital ink recognition: Dividing text and shapes in sketched diagrams", Computers \& Graphics, 2011, 35(5),:976-991.

[26] Balamurugan, A., Rajaram, R., Pramala,S., Rajalakshmi, S., Jeyendran, C., Dinesh Surya Prakash, J., "NB: An improved Naive Bayesianalgorithm", Knowledge-Based Systems, 24(5):563569(2011).

[27] Breiman, L., "Random Forests", Machine Learning, 45(1): 1-34 (2001).

[28] Y. Ma, L. Guo, and B. Cukic, "A Statistical Framework for the Prediction of Fault-Proneness", Advances in Machine Learning Application in Software Engineering, Idea Group Inc., 2006 